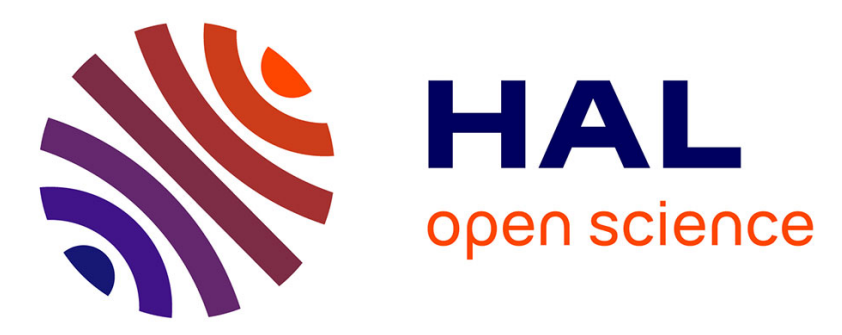

\title{
Treatment of gaseous effluents by using surface discharge plasma in continuous reactors: Process modelling and simulation
}

Aymen Amide Assadi, Abdelkrim Bouzaza, Dominique Wolbert

\section{To cite this version:}

Aymen Amide Assadi, Abdelkrim Bouzaza, Dominique Wolbert. Treatment of gaseous effluents by using surface discharge plasma in continuous reactors: Process modelling and simulation. Canadian Journal of Chemical Engineering, 2015, 93 (2), pp.206-212. 10.1002/cjce.22122 . hal-01154661

\section{HAL Id: hal-01154661 \\ https://hal-univ-rennes1.archives-ouvertes.fr/hal-01154661}

Submitted on 22 May 2015

HAL is a multi-disciplinary open access archive for the deposit and dissemination of scientific research documents, whether they are published or not. The documents may come from teaching and research institutions in France or abroad, or from public or private research centers.
L'archive ouverte pluridisciplinaire HAL, est destinée au dépôt et à la diffusion de documents scientifiques de niveau recherche, publiés ou non, émanant des établissements d'enseignement et de recherche français ou étrangers, des laboratoires publics ou privés. 


\title{
Treatment of gaseous effluents by using surface discharge plasma in continuous reactors: Process modeling and simulation
}

\author{
ASSADI Aymen Amine ${ }^{a . b *}$, BOUZAZA Abdelkrim ${ }^{a, b}$, WOLBERT Dominique a,b \\ a Laboratoire Sciences Chimiques de Rennes - équipe Chimie et Ingénierie des Procédés, UMR 6226 CNRS \\ ENSCR, 11 allée de Beaulieu, 35700 Rennes, France. \\ ${ }^{\mathrm{b}}$ Université Européenne de Bretagne. \\ * Corresponding author. Tel.: +332 23238056; fax: +33223238120. \\ E-mail address: aymen.assadi@ensc-rennes.fr (A.A. Assadi).
}

\begin{abstract}
In the present work, the oxidation of isovaleraldehyde, a typical pollutant of indoor air, is investigated by using two different plasma DBD reactors: cylindrical and planar reactor.

The study of the influence of the specific energy shows that its increment is accompanied by an increase of the removal efficiency. In fact, when specific energy extends three times, the removal efficiency is increased from 5 to $40 \%$. Moreover an increase of the specific energy induces a higher mineralization due to byproducts oxidation with reactive species production. The same behavior is observed with ozone production.

A generic mathematical model is developed to represent the experimental results obtained. This model is based on several mass transfer steps occurring in series between bulk and plasma phases.

The degradation reaction mechanism is supposed to occur on two steps. Firstly, isovaleraldehyde leads to the formation of a fictitious equivalent intermediate (EI).

In a second step, $\mathrm{EI}$ is transformed into $\mathrm{CO}$ and $\mathrm{CO}_{2}$.

This approach gives a good agreement between modeling and experiments with a satisfactory overall description of byproducts formation. This original approach allows for the simulation of plasma oxidation kinetics process without knowing the complete chemical pathway
\end{abstract}

\section{Keywords:}

Plasma DBD, kinetics modeling, VOCs, mass transfer, continuous reactor.

\section{Introduction}


VOCs are hazardous to health and environment; their emission causes serious environmental problems such as stratospheric ozone depletion, photochemical smog, greenhouse effect and so on [1]. Increasing awareness of these emissions has resulted in legislation requiring stringent enforcement of new regulations to improve the quality of the environment [2]. To remove those gaseous pollutants, many technologies have been developed but they are not very successful and do not satisfy the strict social demands of the present. [3] One of the methods which are developed for the control of VOCs is plasma processing. This latest process is a major area of research in both industry and academia [2, 3].

The dielectric barrier discharge (DBD) reactors appear to be most interesting from an economic point of view. Moreover, recently, many research attempts showed the advantages of the DBD reactors for particularly effective control of hazardous gas emissions and treating gas streams with low VOC concentrations at low temperature [4]. The capability for simultaneous removal of coexisting pollutants has also been studied [5]. In fact, the plasma DBD has been widely studied in the area of hazardous and toxic gases control, VOC abatement such as dimethylamine [14], acetylene [6] and benzene [7], $\mathrm{NO}_{\mathrm{x}}$ removal from the flue gas [8]. On the other hand, the DBD plasma even if it seems promising has also some disadvantages [4] such as formations of toxic by-products like $\mathrm{CO}, \mathrm{NO}, \mathrm{NO}_{2}$ and $\mathrm{O}_{3}$. The desired total oxidation to $\mathrm{CO}_{2}$ and $\mathrm{H}_{2} \mathrm{O}$ is usually not achieved $[\mathbf{9 , 1 1 , 1 3}$.

Moreover, a literature review shows that kinetic modeling of plasma DBD reactors has been carried out extensively [10]. The models details kinetic step and a macroscopic diffusionequation are used to describe mass transfer between the micro-discharges and the bulk gas.

The aim of our study is to improve understanding of the physical and chemical mechanisms involved during nonthermal plasma (NTP) degradation process of a typical VOC. In this work, isovaleraldehyde (isoval) is chosen as representative of odorous compounds. It is characterized by low toxicity but is capable to produce health and environmental problems [1]. Isovaleraldehyde produces an oral, dermal and respiratory irritation after exposure and a strong discomfort related with strong odor even at low concentrations [2].

The focus is put on the study of kinetic removal of this pollutant and the effect of some operating parameters. Additionally, a mathematical model is proposed in order to represent the oxidation mechanism in the plasma reactor. 


\section{Experimental}

The experimental units include three major elements: the gas mixture generation system, the continuous reactors and the analysis system.

\subsection{Polluted flow generation}

Figure 1 shows a scheme of the used system. The air flow is obtained from the internal network of compressed air. The flow rate is regulated by a mass flow controller (EL-FLOW F-201AV, Hi-Tec Bronkhorst, Netherlands) reaching a maximum working value of $10 \mathrm{~m}^{3} / \mathrm{h}^{1}$. In order to adjust humidity to suitable values between $40-50 \%$, air stream is passed through a countercurrent humidifier column by a centrifugal pump. The temperature and the relative humidity are measured by TESTO_445 sensor.

Isovaleraldehyde (>99.7\%, Sigma-Aldrich, Switzerland) is injected to the inlet air through a syringe pump with manual refill and with volume of $5 \mathrm{~mL}$. A heating system covering the injection zone sets the gas temperature and facilitates the VOC vaporization ahead of the static mixer. A venturi system is installed to improve the homogenization of the contaminated air previous being introduced into the reactor.

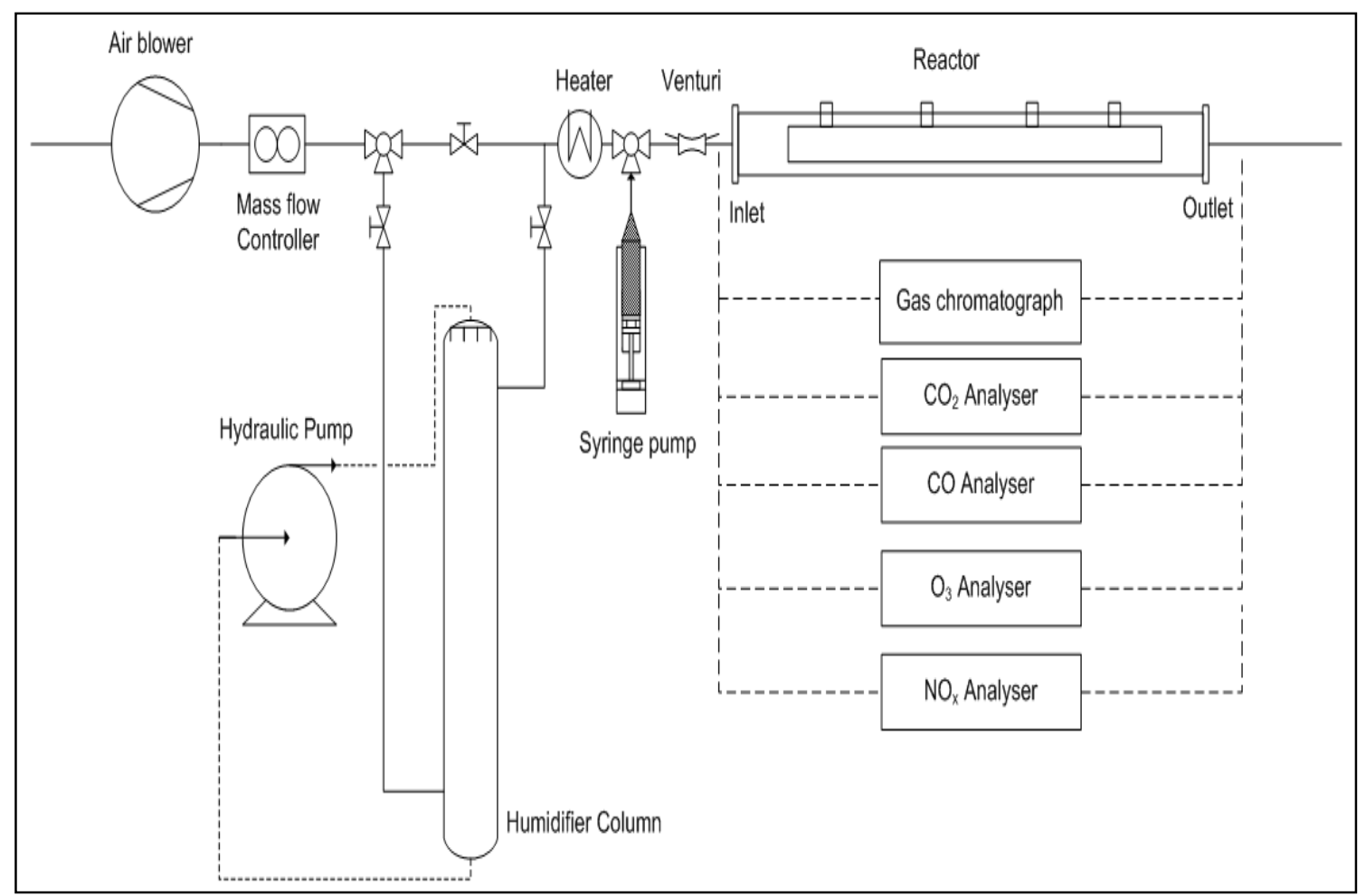

Figure 1: Scheme of experimental set-up 


\subsection{Continuous flow reactors}

The plasma DBD cylindrical reactor is composed principally of a glass tube $(58 \mathrm{~mm}$ id and $100 \mathrm{~cm}$ length) (Figure 2). To generate DBD plasma, the reactor is covered by a copper grid which constitutes the outside electrode. The inner electrode is made from a continuous helical aluminum winding. It is a $2 \mathrm{~mm}$ thickness helicoidally wire electrode shaped as a coil spring in close contact with the inner wall of the reactor $(12$ turns in $250 \mathrm{~mm}$ ). The applied high voltage is about $30 \mathrm{kV} / 40 \mathrm{~mA}$ and is a sine waveform. Plasma DBD is obtained by submitting the electrodes to a sinusoidal high voltage ranging from 0 to $30 \mathrm{kV}$ (peak to peak) at $50 \mathrm{~Hz}$ frequency. A $2.5 \mathrm{nF}$ capacitance is positioned between the outer electrode and the ground connection in order to collect the charges transferred through the reactor (Manley's method). The applied voltage $\left(U_{a}\right)$ and high capacitance voltage $\left(U_{m}\right)$ are measured by LeCroy high voltage probes and recorded by a digital oscilloscope (Lecroy Wave Surfer 24 Xs, $200 \mathrm{MHz}$ ) (Figure 2).

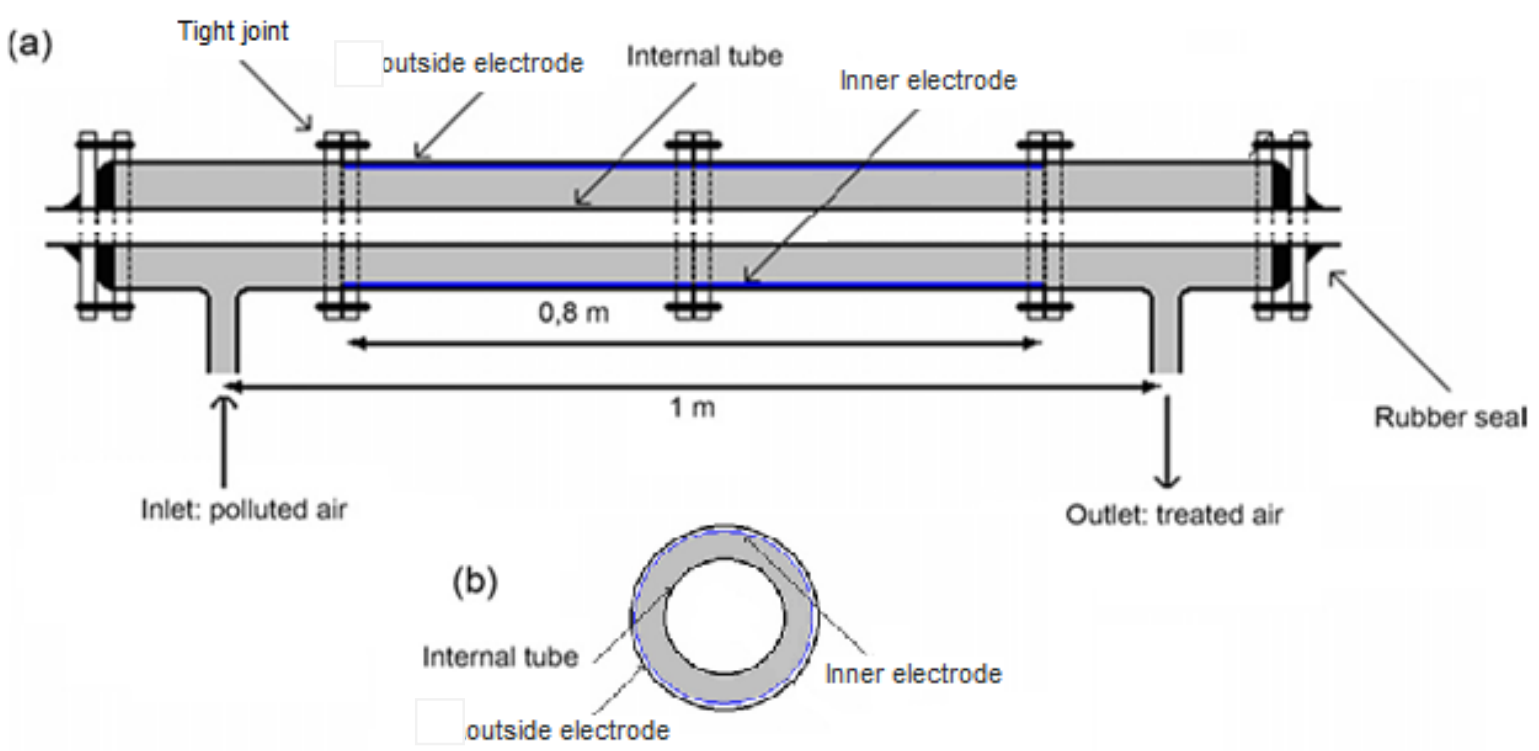

Figure 2: Scheme (a) and sectional drawing (b) of the cylindrical reactor

The planar reactor consists of a rectangular cross section $\left(135 \times 135 \mathrm{~mm}^{2}\right)$ and is $1 \mathrm{~m}$ length. It is made by polymethyl methacrylate (PMMA) material. The length of the active zone is 0.8 $\mathrm{m}$. Its surface is equal to $0.19 \mathrm{~m}^{2}$ (Figure 3). Two plates, $4 \mathrm{~mm}$ thickness, are arranged parallel to the length of the reactor. The nonthermal plasma, of surface dielectric barrier type, is generated by a $2 \mathrm{~mm}$ thickness grid with wire electrodes shaped as a rectangle. The distance 
between two wire electrodes was $20 \mathrm{~mm}$. The outer electrode, connected to the ground, is 1 $\mathrm{mm}$ thick and $80 \mathrm{~cm}$ length copper foil.

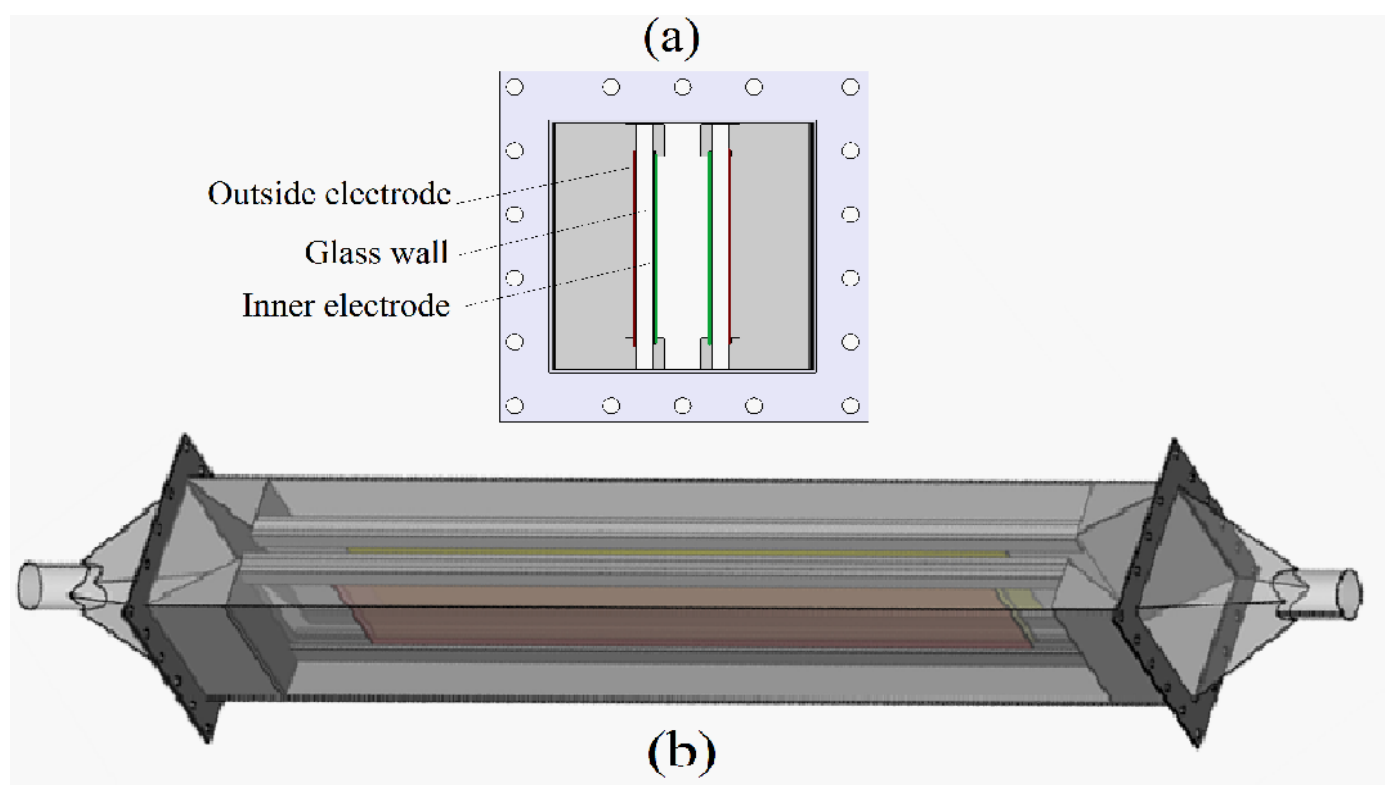

Figure 3: Sectional drawing (a) and Schema (b) of planar reactor.

The effective volumes are 1.5 and 3.75 L for cylindrical and planar reactor respectively.

\subsection{Apparatus and Analysis}

To analyse isovaleraldehyde, FISONS Gas chromatograph coupled with a flame ionization detector (GC-FID) is used as described in the previous study [13].

The inlet and outlet carbon dioxide concentrations are measured by an infrared detector (100 Cosma Beryl ${ }^{\circledR}$, Cosma ${ }^{\circledR}$, Igny, France). CO concentrations can be measured by a CO_ZRE gas analyzer. Standard iodometric titration method was used to estimate the downstream ozone formation. Thus at the exit of the plasma reactor a constant flow rate of $200 \mathrm{~L} / \mathrm{h}$ is bubbled on iodine solution.

Two operating parameters are varied in order to study their influence on the reactor performance: specific energy and geometries of reactors.

Isovaleraldehyde degradation by plasma DBD is evaluated at several specific energies using the two reactors (Table 1).

Table 1: Parameters of plasma DBD reactor 


\begin{tabular}{|c|c|}
\hline Parameter & Value \& domain \\
\hline Gas temperature & Ambient (293 K) \\
\hline Gas pressure & Atmospheric pressure (1atm) \\
\hline Relative humidity & $45 \pm 5 \%$ \\
\hline Geometries of reactors & Planar \& cylindrical \\
\hline Applied voltage & 12 to $29 \mathrm{kV}$ \\
\hline Input power (planar reactor) & 13.8 to $44.3 \mathrm{~W}$ \\
\hline Input power (cylindrical reactor) & 5.6 to $17.7 \mathrm{~W}$ \\
\hline Isovaleraldehyde feed & $400 \mathrm{mg} / \mathrm{h}$ \\
\hline Residence time & $1.5 \mathrm{~s}$ \\
\hline
\end{tabular}

\section{Results and Discussion}

Experimental parameters are defined as follows:

- $\left(\mathrm{C}_{\text {inlet }}\right)$ and $\left(\mathrm{C}_{\text {outlet }}\right)$ represent inlet and outlet concentration of pollutant $\left(\mathrm{mg} / \mathrm{m}^{3}\right)$ respectively. $C_{\text {inlet }}$ varies between 5 and $200 \mathrm{mg} / \mathrm{m}^{3}$.

- Removal efficiency $(\mathrm{RE} ; \%)=100\left(1-\mathrm{C}_{\text {outlet }} / \mathrm{C}_{\text {inlet }}\right)$

- Specific Energy SE $(\mathrm{J} / \mathrm{L})=\left(\mathrm{P}(\mathrm{W}) / \mathrm{Q}\left(\mathrm{m}^{3} / \mathrm{s}\right)\right) / 1000$

where $\mathrm{P}$ is the input power of plasma. The specific energy is varied by changing the applied voltage $\left(\mathrm{U}_{\mathrm{a}}\right)$.

- Energy efficiency $\left.\eta_{\mathrm{E}}(\mathrm{g} / \mathrm{kWh})=\left(\mathrm{C}_{\text {inlet }}-\mathrm{C}_{\text {outlet }}\right)\left(\mathrm{g} / \mathrm{m}^{3}\right) \times \mathrm{Q}\left(\mathrm{m}^{3} / \mathrm{h}\right)\right) / \mathrm{P}(\mathrm{W})$

The experiments which are repeated two times; show a good reproducibility with $5 \%$ standard deviation. This standard deviation is represents by vertical and horizontal bars in the experimental results in all figures.

\subsection{Removal of isovaleraldehyde}

The study of the specific energy effect shows that when this parameter increases the removal efficiency (RE) of isovaleraldehyde increases also (Figure 4). For example, with cylindrical reactor when specific energy extends three times the RE is increased from 5 to $40 \%$. The same behavior is observed with planar reactor. 
This is expected, as increasing electric voltage across the reactor leads to higher degree of ionization and higher reactive species production [6-8]. Therefore the pollutant has more probability to be attacked by electrons or radicals, resulting to an enhancing RE of isovaleraldehyde. The behavior is similar to what has been reported in the literature for some VOCs $[4,10,13]$.

In order to compare the performances of the two reactors with different geometries, isovaleraldehyde flow and residence time are kept constant. Thus the flow rate and the initial isovaleraldehyde concentration are respectively equal to $4 \mathrm{~m}^{3} / \mathrm{h}$ and $100 \mathrm{mg} / \mathrm{m}^{3}$ in the case of cylindrical reactor. There are equal, respectively, to $10 \mathrm{~m}^{3} / \mathrm{h}$ and $40 \mathrm{mg} / \mathrm{m}^{3}$ in planar reactor. However, in practice, energy efficiency is an important parameter. But, we note that regardless of the value of specific energy, the energy efficiency of cylindrical reactor is better than that of planar reactor (Figure 4). In fact, the planar reactor needs more energy to decompose the same amount of isovaleraldehyde. This is probably due to the fact that the mass transfer step is predominant in the planar reactor. In fact, reduction the cross section resulted in an increased $\eta_{\mathrm{E}}$ (4 to $10 \mathrm{~g} / \mathrm{kwh}$ ), suggesting better ionization of the air due to increased contact between air and plasma. This observation was supported by the work of Cal and Schluep [21], that studied two different gap distances between electrodes and observed that a smaller distance between electrodes requires less energy or applied voltage to obtain the same removal efficiency [13, 21]. 


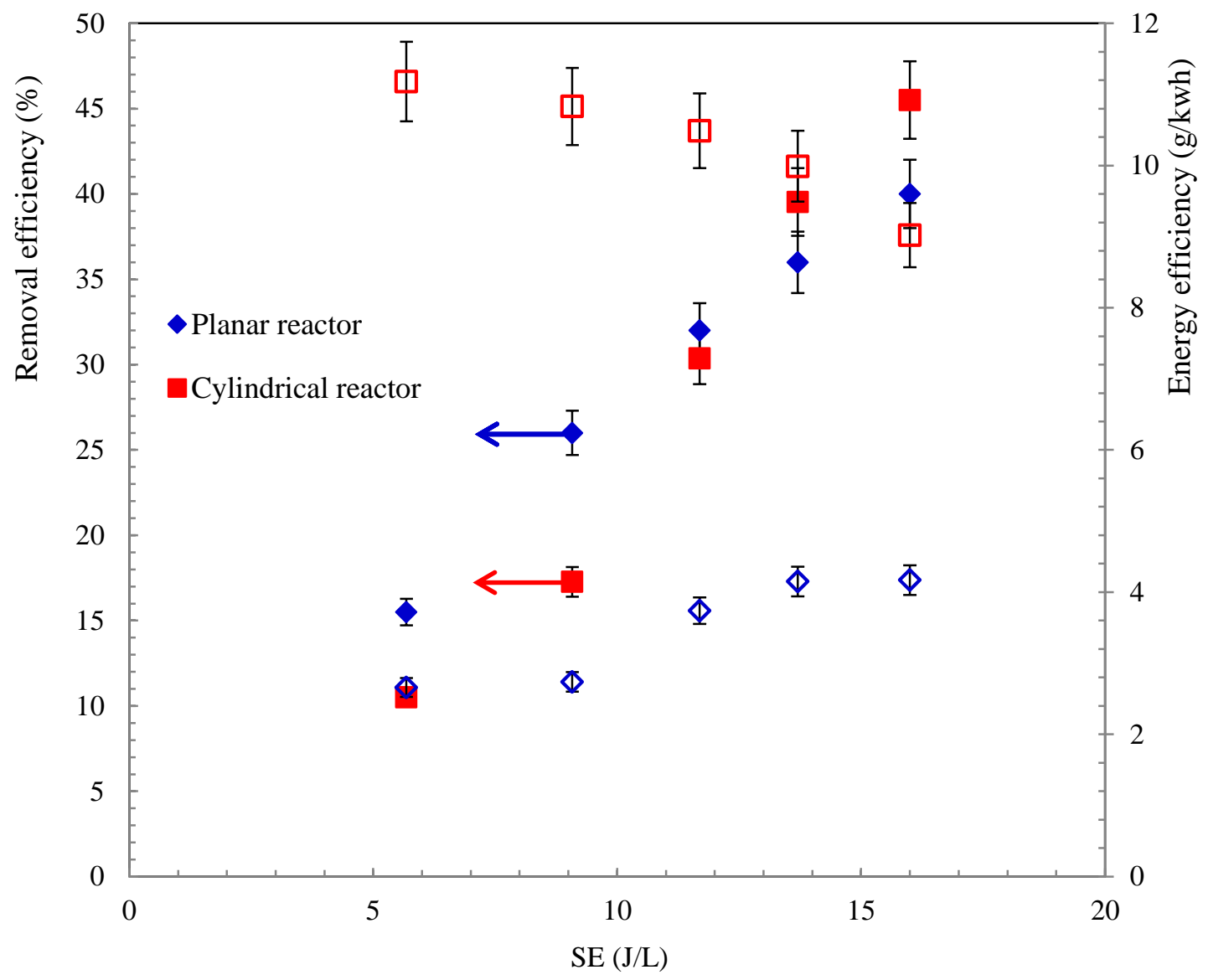

Figure 4: Variation of removal efficiency and energy efficiency vs the specific energy using two reactors (Empty symbols = energy efficiency).

\subsection{Selectivities of $\mathrm{CO}$ and $\mathrm{CO}_{2}$}

$\mathrm{CO}_{2}$ selectivity ( $\mathrm{CO}$ selectivity can also be defined) may be a useful parameter to assess the performance of the plasma DBD reactor towards VOC removal. It allows estimating the mineralization rate i.e. the ultimate reaction step, of the process.

The $\mathrm{CO}_{\mathrm{x}}$ selectivity is expressed as follow (eq.4):

$$
\left\{\mathrm{CO}_{\mathrm{x}} \text { selectivity }(\%)\right\}=\frac{\left[\mathrm{CO}_{\mathrm{x}}\right]^{\text {out }}-\left[\mathrm{CO}_{\mathrm{x}}\right]^{\text {in }}}{5 \times \mathrm{C}_{\text {inlet }} \times(\% \mathrm{RE})} \times 10^{4}
$$

where $\mathrm{x}=1$ for $\mathrm{CO}$ and $\mathrm{x}=2$ for $\mathrm{CO}_{2}$. $\left[\mathrm{CO}_{\mathrm{x}}\right]$ (ppmv) is obtained after the removal of isovaleraldehyde. $\mathrm{C}_{\text {inlet }}$ is the inlet concentration of isovaleraldehyde. 


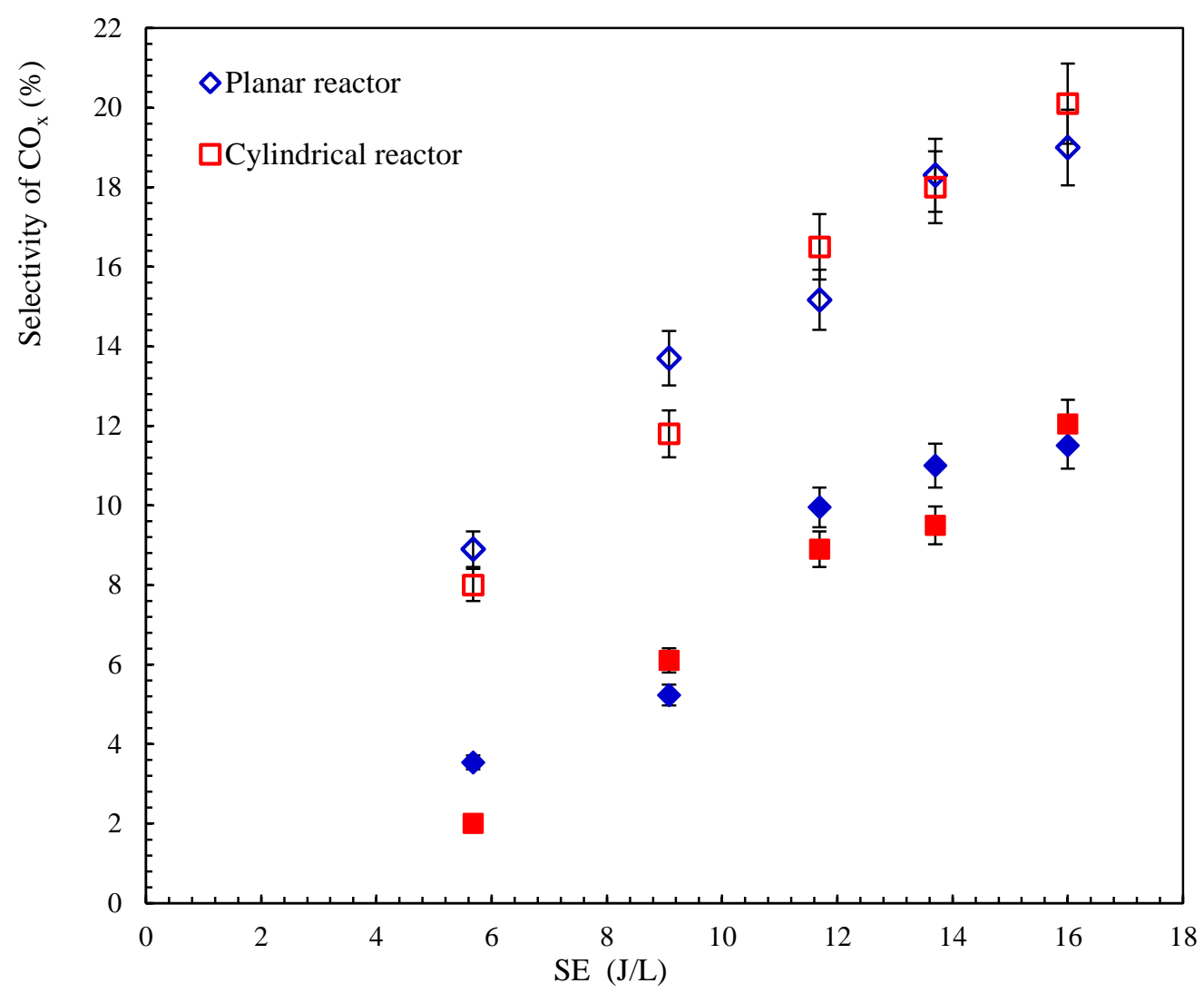

Figure 5: Variation of $\mathrm{CO}_{\mathrm{x}}$ selectivity vs specific energy using two reactors $\left(\right.$ Empty symbol $=$ selectivity of $\mathrm{CO}_{2}$ and full symbol $=$ selectivity of $\left.\mathrm{CO}\right)$.

The increase of specific energy leads to an increase of the selectivities (Figure 5). This is due to more electrons and reactive species (such as ${ }^{\circ} \mathrm{O}$ and ${ }^{\circ} \mathrm{OH}$ ) which are formed when specific energy increases and then more pollutants molecules is oxidized into $\mathrm{CO}_{2}$ and $\mathrm{CO}[\mathbf{1 3}, \mathbf{2 0}]$. In fact, with planar reactor, an increase of specific energy from 9 to $16 \mathrm{~J} / \mathrm{L}$ improves $\mathrm{CO}$ and $\mathrm{CO}_{2}$ selectivity from 3 to $11 \%$ and from 9 to $19 \%$, respectively. The proportion of $\mathrm{CO}_{2}: \mathrm{CO}$ is about 2. Additionally, this proportion is similar at each value of SE. These results are in agreement with works on acetylene degradation with plasma $[\mathbf{5}, \mathbf{6 , 1 1}]$, n-hexane [10], trimethylamine [13] and $\mathrm{NO}_{\mathrm{x}}[\mathbf{8}]$.

Moreover, we can note that selectivity of $\mathrm{CO}_{\mathrm{x}}$ using planar and cylindrical reactors is globally the same. Thus we conclude that changing geometries from cylindrical to planar reactor seems to be satisfied.

\subsection{Amount of Ozone}


Ozone is an inevitable by-product in nonthermal plasma discharge. Atomic oxygen is generated by molecular dissociation due to impact with high energy electrons (reaction 1).

$$
\mathrm{e}^{-}+\mathrm{O}_{2} \rightarrow \mathrm{e}^{-}+{ }^{\circ} \mathrm{O}+{ }^{\circ} \mathrm{O}
$$

Atomic oxygen is a strong oxidizer, but its stability is very limited. Due to fast recombination processes, the lifetime is only a few microseconds at atmospheric pressure [4]. Atomic oxygen reacts with molecular oxygen in three-body collisions, forming ozone by the following reaction:

$$
\cdot \mathrm{O}+\mathrm{O}_{2}+\mathrm{M} \rightarrow \mathrm{O}_{3}+\mathrm{M}
$$

where $\mathrm{M}$ can be either molecular oxygen or molecular nitrogen.

The effect of the specific energy on the ozone formation is presented in figure 6 . Whatever the reactor used, the ozone formation follows the same trend i.e. it increases with the SE.

This can be explained by the fact that more electrons and reactive species (such as ${ }^{\circ} \mathrm{O}$ ) are formed and then atomic oxygen reacts with molecular oxygen in three-body collisions, (reactions $1 \& 2$ ) leading to ozone production $[4,6,19]$.

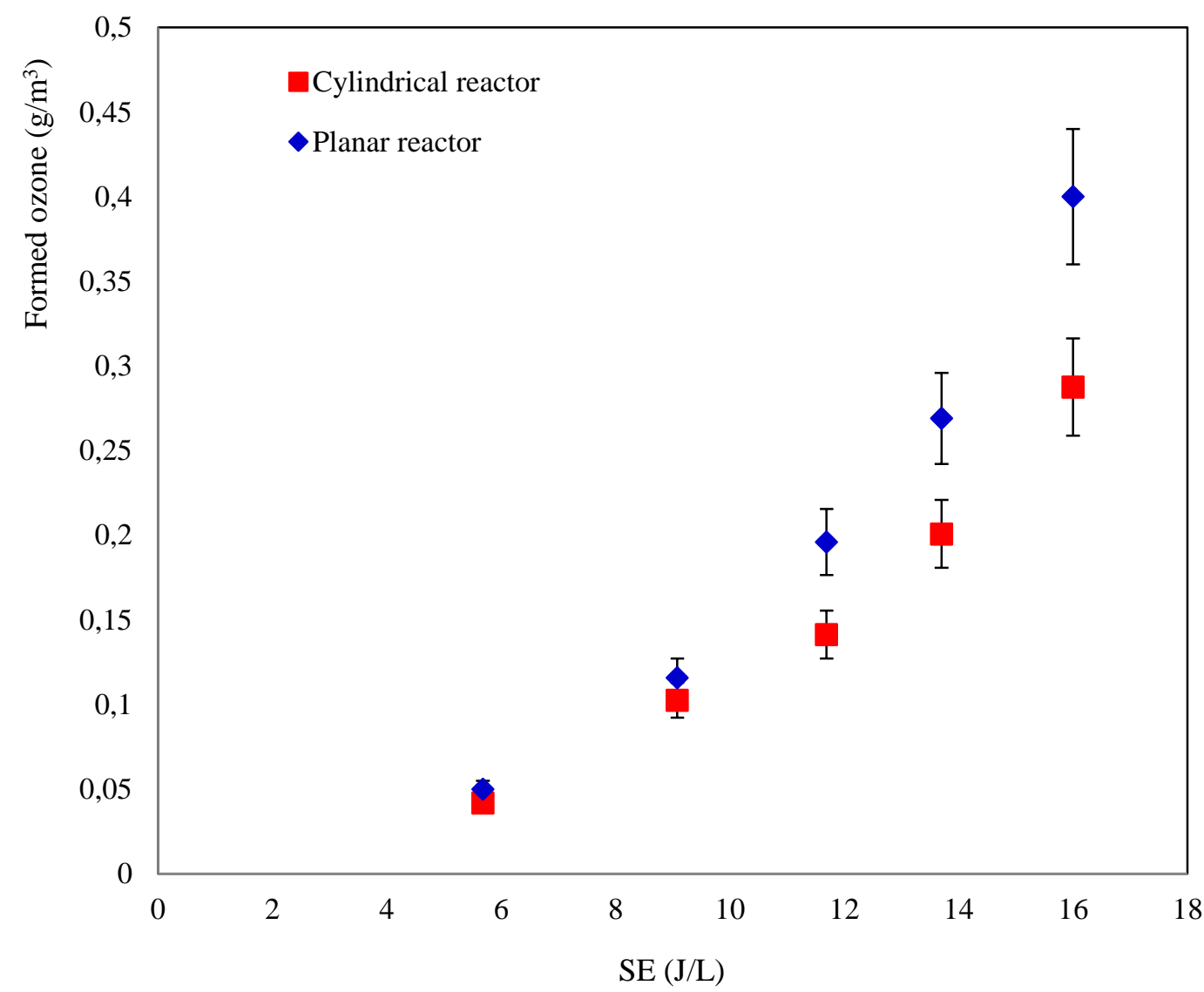

Figure 6:Variation of ozone production vs Specific energy the two reactors $\left(\mathrm{T}=20^{\circ} \mathrm{C}\right)$ 
The difference between the ozone formed in reactors can be due to the energy efficiency. Indeed, having the same amount of active species in reactors, if the mass transfer of isovaleraldehyde to the active zone is limited (case of planar reactor), the exceed of atomic oxygen will recombine for forming ozone (reaction 2). Thus, this result may confirm our suggestion on the difference between energies efficiency in the two reactors.

\section{Modelling and kinetic results}

The main purpose of this work is to establish a predicting model which can be applied to the design of plasma DBD reactors.

\subsection{Mathematical model of the process}

The process may be divided into five elemental steps (Figure 7.a) occurring in series: 1) convection (VOCs and precursor species are carried by airflows), 2) external diffusion of reagent species through the boundary layer (BL) surrounding the plasma phase, 3) chemical reaction at plasma layer 4) counter-diffusion of product(s) to the bulk.

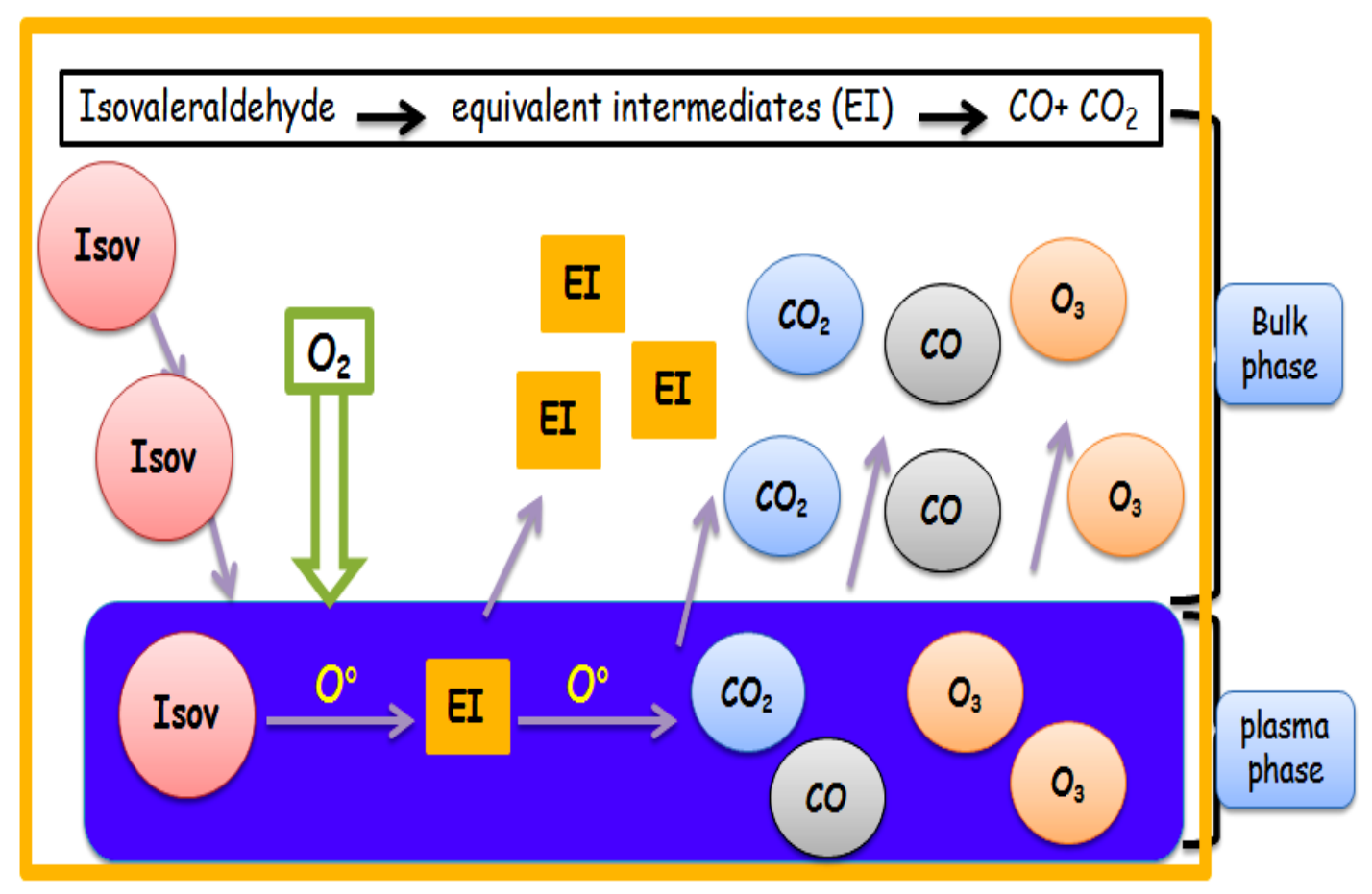

Figure 7.a: Elemental mass transfer steps involved with plasma DBD reactor

\subsubsection{Modeling of mass transfer}


We assumed that the radial convection phenomenon is negligible and that mass transfer between the bulk and plasma regions takes place only through diffusion [10, 11]. We use the correlation of Perry et al. [40] to express the molecular diffusivity $\left(D_{m}\right)$ of each specie " $i$ " in the air. The correlation is as follows:

$$
D_{m, i}=\frac{1.43 \times 10^{-3} \times T^{1.75}}{P\left[\left(\sum v\right)_{A}^{(1 / 3)}+\left(\sum v\right)_{i}^{(1 / 3)}\right]^{2}}\left(\frac{1}{M_{A}}+\frac{1}{M_{i}}\right)^{0.5}
$$

where $\mathrm{P}$ is the pressure of gas stream $(\mathrm{Pa}), \mathrm{T}$ the absolute temperature $(\mathrm{K}) .\left(\sum \mathrm{v}\right)_{\mathrm{A}}$ and $\left(\sum \mathrm{v}\right)_{\mathrm{i}}$ are the molecular volumes of gases $\mathrm{A}$ and $\mathrm{i}$, and $\mathrm{M}_{\mathrm{A}}$ and $\mathrm{M}_{\mathrm{i}}$ are the molecular weights of $\mathrm{A}$ and $\mathrm{i}(\mathrm{g} / \mathrm{mol})$. The index " $\mathrm{A}$ " represents the air stream and " $\mathrm{i}$ " is either specie.

\subsubsection{Modeling of kinetic reaction}

It will always be difficult to perform a complete analysis of all byproducts present at any given time during the degradation process. Thus we propose to develop a chemical pathway involving one or more equivalent intermediates. The modeling is done by introducing a fictitious equivalent intermediate (EI) formed by the plasma oxidation of isovaleraldehyde. In a first chemical step, isovaleraldehyde leads to EI formation. Then, at a second chemical step, $\mathrm{EI}$ is transformed into $\mathrm{CO}$ and $\mathrm{CO}_{2}$. This approach allows for the simulation of kinetics without knowing the complete chemical pathway [23]. Thus, for a single EI, the simplified chemical pathway would be:

$$
\begin{aligned}
& \text { Isovaleraldehyde } \stackrel{\mathrm{k}_{1}}{\longrightarrow} \mathrm{EI} \stackrel{\mathrm{k}_{2}}{\longrightarrow} 5 \mathrm{CO}_{2} \\
& \text { Isovaleraldehyde } \stackrel{\mathrm{k}_{1}}{\longrightarrow} \mathrm{EI} \stackrel{\mathrm{k}_{3}}{\longrightarrow} 5 \mathrm{CO}
\end{aligned}
$$

Simulation model is based on the hypothesis that the pollutant is degraded through the plasma layer.

Since plasma DBD is generated in a gas mixture where nitrogen and oxygen are the main components, the model developed here includes a first set of reactions based on the air discharge models available in the literature $[\mathbf{1 0}, \mathbf{1 6}, \mathbf{1 7}]$. The model takes into account only one species: atomic oxygen.

The electron concentration, averaged over several cycles, can be considered proportional to a power of the specific energy: 


$$
\mathrm{C}_{\mathrm{e}-}=\alpha \cdot \mathrm{E}_{\mathrm{Z}}^{\alpha_{\mathrm{E}, 1}}
$$

The reaction between electrons and oxygen can be written as follows:

$$
\mathrm{r}=-\mathrm{k} \cdot \mathrm{C}_{\mathrm{e}-} \cdot\left[\mathrm{O}_{2}\right]=-\mathrm{k}^{\prime} \cdot \mathrm{E}_{\mathrm{Z}}^{\alpha_{\mathrm{E}, 1}} \cdot\left[\mathrm{O}_{2}\right]
$$

It is generally accepted that the plasma effect can be modeled by the general expression (eq.8):

$$
R_{P, i}(t, x, z)=\sum_{\mathrm{j}=1}^{\mathrm{nr}} \vartheta_{\mathrm{i}, \mathrm{j}} \cdot \mathrm{k}_{\mathrm{j}} \cdot \mathrm{E}_{\mathrm{z}}^{\alpha_{\mathrm{E}, \mathrm{j}}}(\mathrm{t}) \cdot \prod_{\mathrm{p}=1}^{\mathrm{nc}} \mathrm{C}_{\mathrm{i}}^{\gamma_{\mathrm{p}, \mathrm{j}}}(\mathrm{t}, \mathrm{x}, \mathrm{z})
$$

where $R_{p}$ is the removal rate in plasma phase, $E$ is the specific energy of plasma, $C_{i}$ is the concentration of each compound in the plasma layer and $\mathrm{k}_{\mathrm{j}}$ is the constant rate, $\mathrm{t}$ is time, $\mathrm{z}$ is the distance which is perpendicular of flow in plasma zone (film thickness), $\mathrm{x}$ the distance in the direction of flow, $\vartheta_{\mathrm{i}, \mathrm{j}}$ are stoichiometric coefficients of the removal reaction, $\alpha_{\mathrm{E}, \mathrm{j}}, \gamma_{\mathrm{p}, \mathrm{j}}$ are orders of reaction, $\mathrm{n}_{\mathrm{c}}$ and $\mathrm{n}_{\mathrm{r}}$ are respectively number of compounds and reactions

\subsubsection{Mass balance in the reactor}

The mass balance in bulk phase (Eq. (9) and plasma phase (Eq. (10)) can be written as:

$$
\begin{aligned}
& -u_{b} \cdot \frac{\partial C_{b, i}(t, x)}{\partial x}-\frac{\partial C_{b, i}(t, x)}{\partial t}+D_{L} \frac{\partial^{2} C_{b, i}(t, x)}{\partial x^{2}}+a_{b} \cdot T_{B P}=0 \\
& -\frac{\partial C_{i}(t, x, z)}{\partial t}-u(z) \cdot \frac{\partial C_{i}(t, x, z)}{\partial x}+D_{i} \frac{\partial^{2} C_{i}(t, x, z)}{\partial z^{2}}-R_{P, i}(t, x, z)=0
\end{aligned}
$$

Where $C_{b, i}$ is the concentration of each compound in bulk phase, $D_{L}$ is axial dispersion coefficient and $D_{i}$ is molecular diffusion coefficient of each compound, $u_{b}$ is the velocity in bulk phase and $\mathrm{T}_{\mathrm{BP}}$ is the mass flow rate from bulk to plasma phase: $T_{B P}=-\left.D_{i} \frac{\partial C_{i}}{\partial z}\right|_{z=e}$ Moreover, $\mathrm{u}(\mathrm{z})$ is the velocity in plasma phase. It can be expressed as:

$$
u(z)=u_{b} \cdot\left(\frac{z}{e}\right)^{2}
$$

Where e is the thickness of plasma streamer [24].

Figure 7.b shows the profile of velocity in plasma and bulk phase. Here we supposed that boundary layer and plasma zone haven the same thickness. 


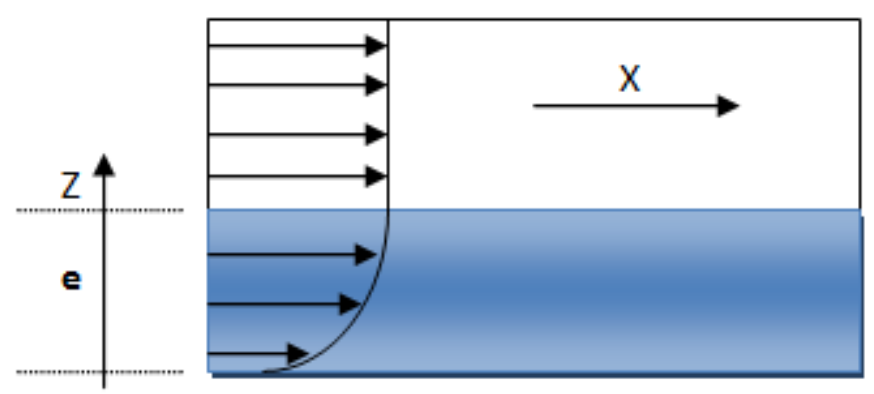

Figure 7.b: Profile of velocity in plasma and bulk phase of reactor

The boundary and initial conditions are as follows:

$$
\begin{aligned}
& C_{b, i}(t, x=-\infty)=C_{0}(t) \\
& C_{b, i}(t, x=+\infty)=0 \\
& C_{i}(t, x, e)=C_{b, i}(t, x) \\
& \text { At } \mathrm{t}=0, C_{b, i}(0, x)=0
\end{aligned}
$$

\subsection{Model fitting and results}

After having defined the plasma model, the fitting was performed on the total duration of all the experiments based on the experimental concentrations of isovaleraldehyde, ozone, $\mathrm{CO}$ and $\mathrm{CO}_{2}$ formed. Additionally, the resolution of the partial differential equation set is carried out by using orthogonal collocation. The Gear's predictor-corrector multistep method is applied to the equation set. A Gauss-Newton method is implemented to determinate the values of some parameters, especially, kinetics constants $\left(\mathrm{k}_{\mathrm{j}}\right)$, by a least square fitting of the relative difference between simulated and experimental concentrations [23].

After optimization, the values of constants $\mathrm{k}_{1}, \mathrm{k}_{2}, \mathrm{k}_{3}$ and $\mathrm{k}\left(\mathrm{O}_{3}\right)$ are summarized in Table 2 .

Table 2: Values of constants

\begin{tabular}{|c|c|c|c|c|}
\hline Kinetic constant & $\mathrm{k}_{1}\left(\mathrm{~m}^{3} \cdot \mathrm{mol}^{-1} \cdot \mathrm{s}^{-1}\right)$ & $\mathrm{k}_{2}\left(\mathrm{~m}^{3} \cdot \mathrm{mol}^{-1} \cdot \mathrm{s}^{-1}\right)$ & $\mathrm{k}_{3}\left(\mathrm{~m}^{3} \cdot \mathrm{mol}^{-1} \cdot \mathrm{s}^{-1}\right)$ & $\mathrm{k}\left(\mathrm{O}_{3}\right)\left(\mathrm{s}^{-1}\right)$ \\
\hline Values & $1.21 .10^{-02}$ & $1.31 .10^{-02}$ & $5.60 .10^{-04}$ & $2.70 .10^{-04}$ \\
\hline
\end{tabular}

Figure 8 shows the evolution versus time of the transitory isovaleraldehyde outlet concentration and final products resulting from plasma DBD reaction. Here, plasma is 
switched ON after $20 \mathrm{~min}$. After this period, Figure 8 shows that all the concentrations of byproducts are stables. Moreover, an increase of specific energy after $45 \mathrm{~min}$ is done in order to see the behavior of the process due to a modification in operating parameters.

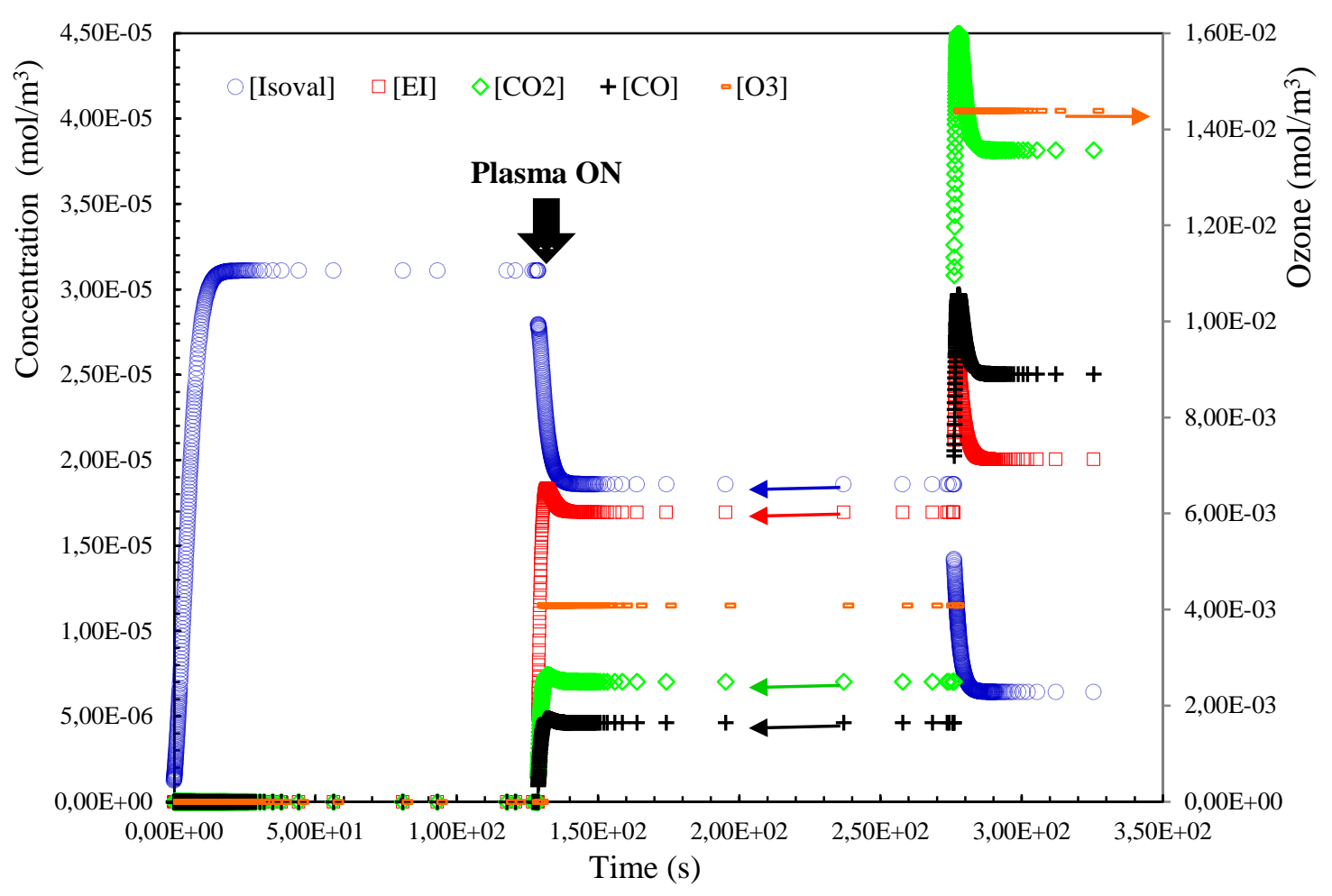

Figure 8: Computed concentration of the outlet of isovaleraldehyde and byproducts versus time ([Isovaleraldehyde $\left.]_{0}=0.03 \mathrm{mmol} / \mathrm{m}^{3}, \mathrm{Q}=10 \mathrm{~m}^{3} / \mathrm{h}, \mathrm{T}=25^{\circ} \mathrm{C}\right)$

Numerical resolution of equations (7) and (8) will give outlet isovaleraldehyde concentration, selectivity of $\mathrm{CO}_{\mathrm{x}}$ and amount of ozone at different operating parameters for each reactor and at each inlet concentration.

The comparisons between experimental and predicted results are represented on figure 9 . 

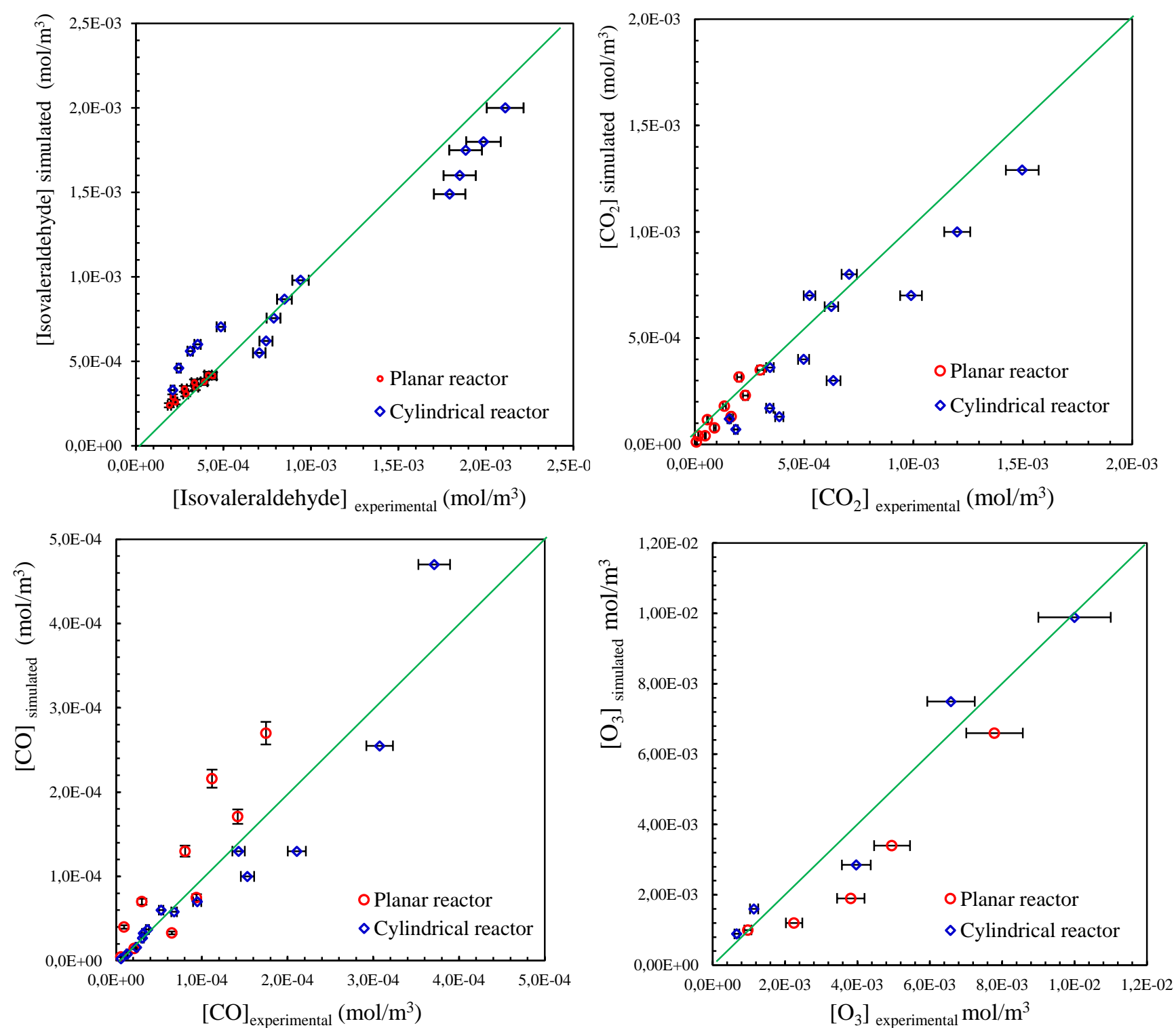

Figure 9: Comparison of simulated results vs. experimental results at different specific energy and inlet concentration using two geometries of reactor.

We note that the model agrees well with the experimental results. It gives a satisfactory overall description of isovaleraldehyde removal using two geometries of reactor. Moreover, predicted outlet concentrations compared with experimental results show a root mean square error less than $10 \%$. These results are very convincing, particularly because no adjustable parameters have been used to simulate cylindrical and planar reactor.

So, the description of the degradation kinetics of isovaleraldehyde by a model with a single EI can sufficiently properly reproduce the degradation process.

On other hand, the model takes the effect of the specific energy, and it can predict the effect the air gap of the plate of planar reactor. This will allow us to establish a compromise between 
the residence time and the limitation of mass transfer when using surfacic plasma discharge. Otherwise the prediction will give us an estimating of the industrial reactor design which can treat a real industrial flow (more than $1000 \mathrm{~m}^{3} / \mathrm{h}$ ) and with obligation on the outlet concentration of pollutant.

\section{Conclusion}

The removal of isovaleraldehyde is investigated in two continuous reactors with plasma DBD. We have unambiguously shown that removal efficiency of isovaleraldehyde can be improved by increasing specific energy in the discharge area.

The effect of the reactor's geometry on (i) the conversion of isovaleraldehyde (ii) and byproducts formation are tested. Experimental results show that the performance of tested reactors is globally the same.

A kinetic model taking into account mass transfer step is developed. To improve the model concerning mineralization and to describe well the removal of isovaleraldehyde, we included in the chemical pathway of degradation an equivalent background intermediate product (EI) which was formed directly from the initial compound.

This model describes successfully the degradation of isovaleraldehyde by a plasma DBD discharge.

Moreover, the effect of specific energy on selectivity of $\mathrm{CO}, \mathrm{CO}_{2}$ and the amount of ozone formed was studied. By-products formation was well simulated by the model.

\section{Acknowledgment}

This research was supported by the French National Research Agency (ANR) and the authors wish to thank it 


\section{References}

[1] ADEME (2005) Pollutions olfactives : origine, législation, analyse, traitement. ADEME, Dunod, Angers.

[2] CITEPA (2011) Emissions dans l'air en France métropole-substance relative à l'acidification, l'eutrophisation et à la pollution photochimique.

[3] Le Cloirec P. (2004) COV (composés organiques volatils) Technique de l'Ingénieur. G1835.

[4] Vandenbroucke A. M., Morent R., De Geyter N., Leys Ch. (2011) Non-thermal plasmas for non-catalytic and catalytic VOC abatement, Journal of Hazardous Materials 195, 30-54.

[5] Allegraud K. (2008) Décharge à barrière diélectrique de surface : physique et procédé, thèse Ecole polytechnique de Paris.

[6] Redolfi M., Aggadi N., Duten X., Touchard S., Pasquiers S., Hassouni K. (2009) Oxidation of Acetylene in Atmospheric Pressure Pulsed Corona Discharge Cell Working in the Nanosecond Regime, Plasma Chemistry Plasma Processing 29,173-195.

[7] Schmid S., Jecklin M.C., Zenobi R. (2010) Degradation of volatile organic compounds in a non-thermal plasma air purifier, Chemosphere, 79, 124-130.

[8] Yoshida K. (2013) Diesel NOx aftertreatment by combined process using temperature swing adsorption, nonthermal plasma, and NOx recirculation: NOx removal accelerated by conversion of $\mathrm{NO}$ to $\mathrm{NO}_{2}$, Journal of the Taiwan Institute of Chemical Engineers, 44,10541059

[9] Assadi A.A. (2012) Développement d'un procédé de couplage réacteur plasma DBDréacteur photocatalytique pour le traitement des effluents gazeux : du laboratoire à l'application industrielle, Thèse $\mathrm{n}^{\circ} 009$. Rennes: ENSC Rennes.

[10] Aggadi N., (2006) Étude de la réactivité de suies modèles de n-hexane sous décharge couronne pulsée à la pression atmosphérique, Université de Paris Nord-France 
[11] Guaitella O., Thevenet F., Puzenat E., Guillard C., Rousseau A. (2008) $\mathrm{C}_{2} \mathrm{H}_{2}$ oxidation by plasma/ $/ \mathrm{TiO}_{2}$ combination: Influence of the porosity and photocatalytic mechanisms under plasma exposure, Applied Catalysis B: Environmental 80, 296-305.

[12] Sivachandiran L., Thevenet F., Rousseau A. (2013) Non-Thermal Plasma Assisted Regeneration of Acetone Adsorbed $\mathrm{TiO}_{2}$ Surface, Plasma Chemistry Plasma Processing 33, $855-871$.

[13] Assadi A. A., Bouzaza A., Wolbert D. Removal of trimethylamine and isovaleric acid from gas streams in a continuous flow surface discharge plasma reactor, Chemical engineering research and design, in press.

[14] Ye Zh., Zhao J., Huang H. y., Ma F., Zhang R. (2013) Decomposition of dimethylamine gas with dielectric barrier discharge, Journal of Hazardous Materials 260, 32-39

[15] Zhu T., Li J., Liang W., Jin Y. (2009) Synergistic effect of catalyst for oxidation removal of toluene, journal of Hazardous Materials 165, 1258-1260.

[16] Yan K., Van Heesch E.J.M., Pemen A.J.M., Huijbrechts P.A.H.J. (2001) From chemical kinetics to streamer corona reactor and voltage pulse generator, Plasma Chemistry Plasma Processing. 21 (1) 107-137.

[17] Mokt Y. S., Lee Ho W., Hyun Y. J., Ham S. W., Nam I. S. (2001) Determination of Decomposition Rate Constants of Volatile Organic Compounds and Nitric Oxide in a Pulsed Corona Discharge Reactor, Korean journal Chemical Engineering 18, 711-718.

[18] Perry R.H., Green D., Maloney J.O., (1997) $7^{\text {th }}$ edition. New-York, Mc Graw-Hill Book Company.

[19] Subrahmanyam Ch., Renken A., Kiwi-Minsker L. (2010) Catalytic non-thermal plasma reactor for abatement of toluene, Chemical Engineering Journal 160, 677-682. 
[20] Wang H., Li D., Wu Y., Li J., Guofeng L.(2009) Removal of four kinds of volatile organic compounds mixture in air using silent discharge reactor driven by bipolar pulsed power, Journal of Electrostatics 67, 547-555.

[22] Cal M.P., Schluep M. (2001) Destruction of Benzene with Non-Thermal Plasma in Dielectric Barrier Discharge Reactors, Environmental Progress. 20, 151-156.

[23] Brosillon S., Lhomme L., Wolbert D. (2011) Modelling of a falling thin film deposited photocatalytic step reactor for water purification: Pesticide treatment, Chemical Engineering Journal 169 (1-3) 216-225.

[24] Allegraud K., Guaitella O., Rousseau A. (2007) Spatio-temporal breakdown in surface DBDs: evidence of collective effect, Journal of Physics D: Applied Physics 40, 7698-7706. 